Original Research

\title{
Fabrication and characterization of microstructure-controllable COL- HA-PVA hydrogels for cartilage repair
}

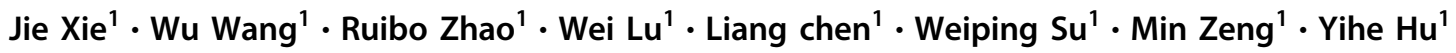

Received: 15 November 2020 / Accepted: 14 June 2021 / Published online: 18 August 2021

(c) The Author(s) 2021

\section{Abstract}

Polyvinyl alcohol (PVA) hydrogel has gained interest in cartilage repair because of its highly swollen, porosity, and viscoelastic properties. However, PVA has some deficiencies, such as its poor biocompatibility and microstructure. This research aimed to design novel hydroxyapatite (HA)-collagen (COL)-PVA hydrogels. COL was added to improve cell biocompatibility, and the microstructure of the hydrogels was controlled by fused deposition modeling (FDM). The feasibility of the COL-HA-PVA hydrogels in cartilage repair was evaluated by in vitro and in vivo experiments. The scanning electron microscopy results showed that the hybrid hydrogels had interconnected macropore structures that contained a COL reticular scaffold. The diameter of the macropore was $1.08-1.85 \mathrm{~mm}$, which corresponds to the diameter of the denatured PVA column. The chondrocytes were then seeded in hydrogels to assess the cell viability and formation of the cartilage matrix. The in vitro results revealed excellent cellular biocompatibility. Osteochondral defects ( $8 \mathrm{~mm}$ in diameter and $8 \mathrm{~mm}$ in depth) were created in the femoral trochlear of goats, and the defects were implanted with cell-seeded hydrogels, cell-free hydrogels, or a blank control. The in vivo results showed that the COL-HA-PVA hydrogels effectively repaired cartilage defects, especially the conditions inoculated with chondrocyte in advance. This research suggests that the COL-HA-PVA hydrogels have promising application in cartilage repair.

\section{Graphical Abstract}
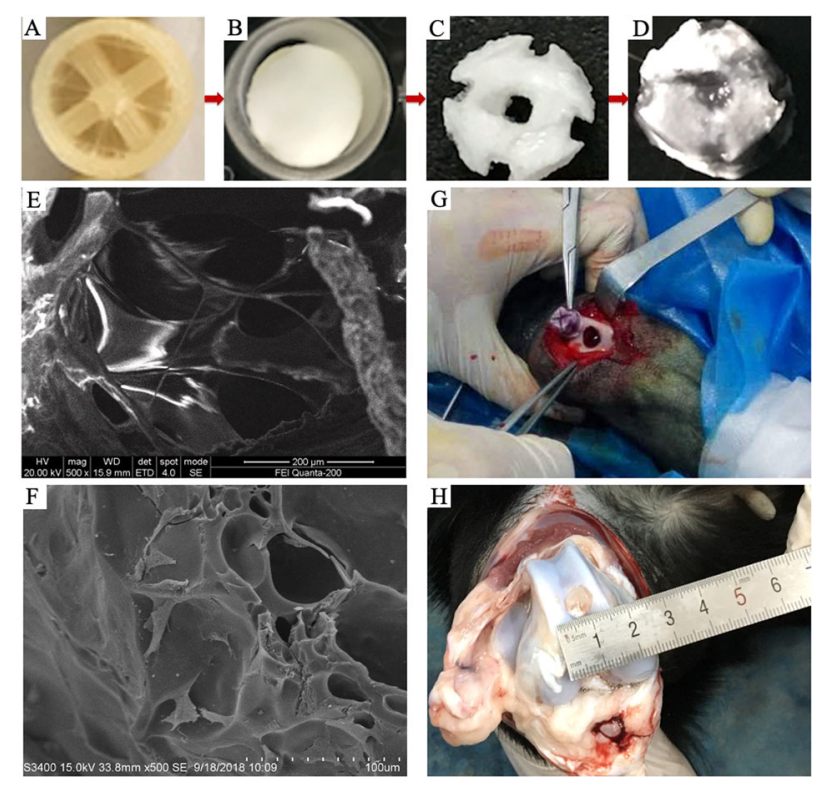

These authors contributed equally: Jie Xie, Wu Wang

Min Zeng

xy_zengmin@163.com

$\triangle$ Yihe $\mathrm{Hu}$

orthop_huyh@163.com
1 Department of Orthopaedics, Xiangya Hospital, Central South University, Changsha, Hunan, China 


\section{Introduction}

Cartilage injury has become a major public health problem because of the aging population and an increase in accident injuries [1-3]. Cartilage damage often results in an underlying bone defect and subsequently, joint dysfunction, because of the absence of vasculature and limited proliferative capacity of native cartilage $[4,5]$. One strategy of growing interest in cartilage repair is artificial cartilage substitutes [6-8]. Numerous studies have demonstrated that hydrogels, such as a polyvinyl alcohol (PVA) hydrogel, have potential as repair materials because of their ability to swell, porosity, and viscoelastic properties [9-12]. However, the poor biocompatibility and limited mechanical property of a pure PVA hydrogel restrict its further application [13, 14]. Previous studies have indicated that hydroxyapatite (HA) and collagen (COL) can be added to a PVA hydrogel to improve the mechanical properties and biocompatibility of the hydrogel $[15,16]$. Chen et al. constructed a polyacrylic acid (PAA)/ PVA-HA composite hydrogel with the mechanical property that improved with the addition of HA particles [17]. Bates et al. added a COL-mimicking peptide to the PVA hydrogel and found that the COL-modified PVA encourages cell attachment while maintaining its compatibility [18]. In addition, our previous research indicated that the mechanics of a novel modified HA/PVA hydrogel were similar to those of native cartilage [19].

The uncontrollable macrostructure and poor microporous structure of a pure PVA hydrogel prepared using a routine method typically result in low integration with cartilage defects and have limited cartilage ingrowth [20, 21]. In addition, a cartilage substitute may be difficult to biologically integrate with peripheral native cartilages, thus leading to implant loosening. Three-dimensional printing (3DP), also known as rapid prototyping and additive manufacturing, can be used to regulate the three-dimensional structure of the hydrogel [7, 22, 23]. Liu et al. designed a porous chitosan (CS)/PVA hydrogel by 3DP for tissue regeneration [24]. Meng et al. revealed that an enhanced mechanical property of the PVA hybrid hydrogel is achieved by 3DP, which suggests a promising potential in the field of cartilage repair [7].

This study used fused deposition modeling (FDM) printing technology, a type of 3DP, to mold a new hybrid PVA hydrogel. Though hydrogels are typically denatured at high temperature because of thermal instability, which prevents gel formation, we found that the denatured PVA could be completely dissolved in double steamed water. In this study, we added a PVA solution to a denatured PVA mold, and the compound PVA was successively processed by melt freeze-dry crosslinking and double steam water demolding. New PVA hydrogels were formed, and the macro-microstructure of the porous PVA hydrogel could be controlled by computer-aided design (CAD). The general structure of the hydrogel can be precisely customized to make the artificial cartilage perfectly fit the defective surface, and the microstructure facilitates material exchange and cell ingrowth. In addition, COL and HA components were added to PVA scaffolds, simulating the natural extracellular matrix components and improving the mechanical properties, respectively. The macropores of the PVA hydrogel contain a COL reticular structure, which favors cell adhesion and subsequently, cartilage ingrowth. In the hybrid PVA hydrogels, the HA-PVA hydrogels simulate the characteristics of the viscoelastic material of natural cartilage and provide mechanical support, while the filled, degrading cell-loaded COL microscaffolds allow for neo-tissue formation and integration with peripheral native cartilage. The application possibility of the COL-HA-PVA hydrogels was evaluated through a series of in vitro and in vivo experiments.

\section{Materials and methods}

\subsection{Fabrication and evaluation of COL-HA-PVA hydrogels}

\subsubsection{COL-HA-PVA hydrogels preparation}

Using FDM technology, PVA powder was melted in the printing head, and the thermoplastic PVA was arranged with a specific protocol, which contributes to the formation of the denatured PVA mold. The cylinder PVA scaffold has a diameter of $8 \mathrm{~mm}$ and a height of $8 \mathrm{~mm}$, and the diameter of the PVA thread in the printing head was 1.2, 1.4, 1.6, 1.8, or $2.0 \mathrm{~mm}$, respectively, which provided the basis of grouping for further experiments (Fig. 1A).

The HA-PVA hydrogels were prepared through repeated freeze-drying and molding (Fig. 1B, C). Specifically: (1) mechanical blending of $15 \mathrm{wt} \%$ PVA and $5 \mathrm{wt} \%$ HA powder in double-distilled water with a magnetic stirrer [25, 26]; (2) transferring the HA-PVA emulsion into the denatured PVA mold to form a mixed structure; (3) freezing the mold/mixture at $-20^{\circ} \mathrm{C}$ for $10 \mathrm{~h}$ and thawing for $2 \mathrm{~h}$ at room temperature, repeating the process five times; (4) immersing the mixture in double-distilled water and stirring continuously to dissolve the denatured PVA mold; (5) freeze-drying the HA-PVA hydrogels for $24 \mathrm{~h}\left(-80^{\circ} \mathrm{C}, 0 \mathrm{MPa}\right)$.

The COL-HA-PVA hydrogels were prepared with freeze drying using genipin as a cross-linking agent (Fig. 1D). Specifically: (1) immersing the HA-PVA hydrogels in a $5 \mathrm{mg} / \mathrm{ml} \mathrm{COL} \mathrm{I}$ solution and centrifuging for $5 \mathrm{~min}$ to completely impregnate the pores of the hydrogels; (2) freezing the composite for $24 \mathrm{~h}$ at $-20^{\circ} \mathrm{C}$ and $12 \mathrm{~h}$ at $-80^{\circ} \mathrm{C}$, and then freeze-drying for $24 \mathrm{~h}$ in a freeze dryer $\left(-80^{\circ} \mathrm{C}, 0 \mathrm{MPa}\right)$, which forms the $\mathrm{COL}$ microscaffold in 

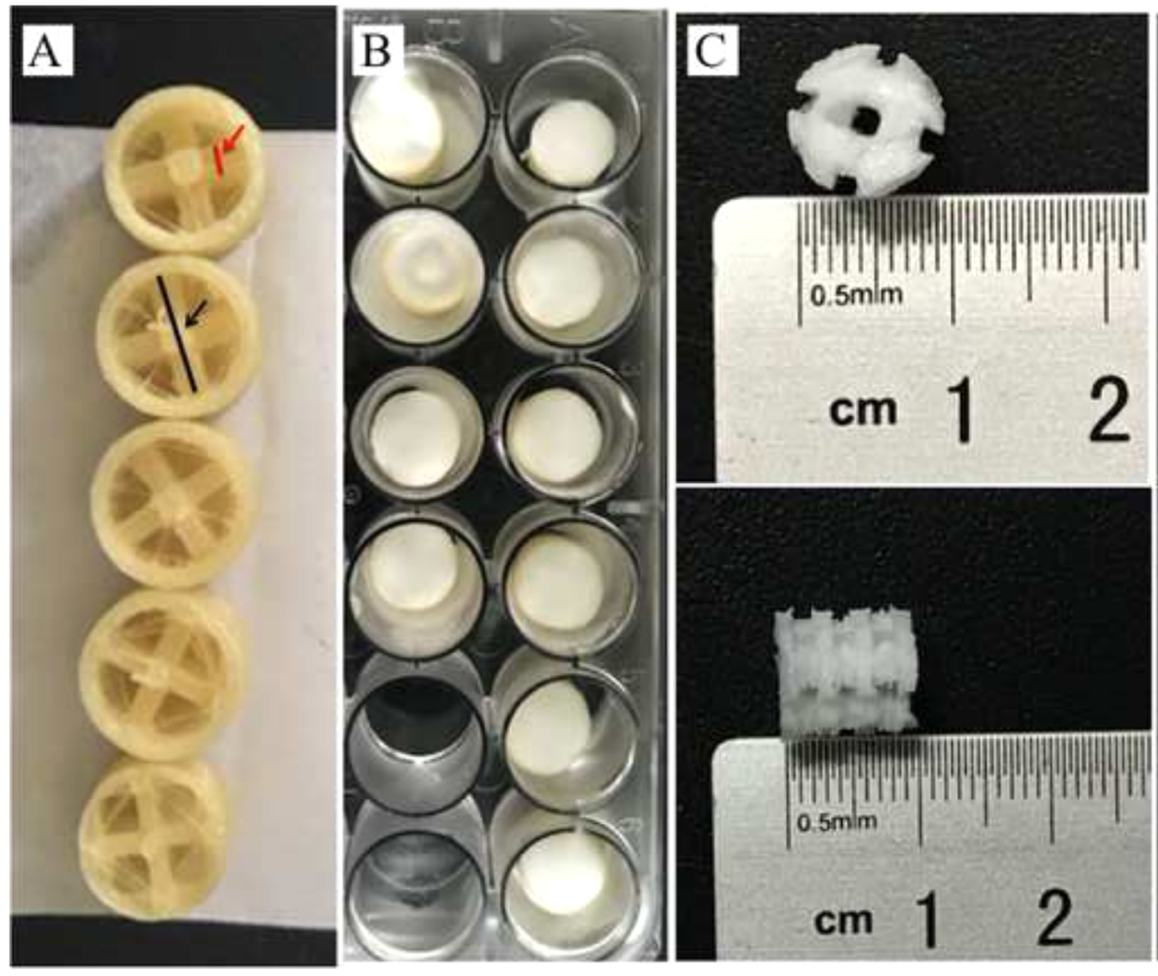
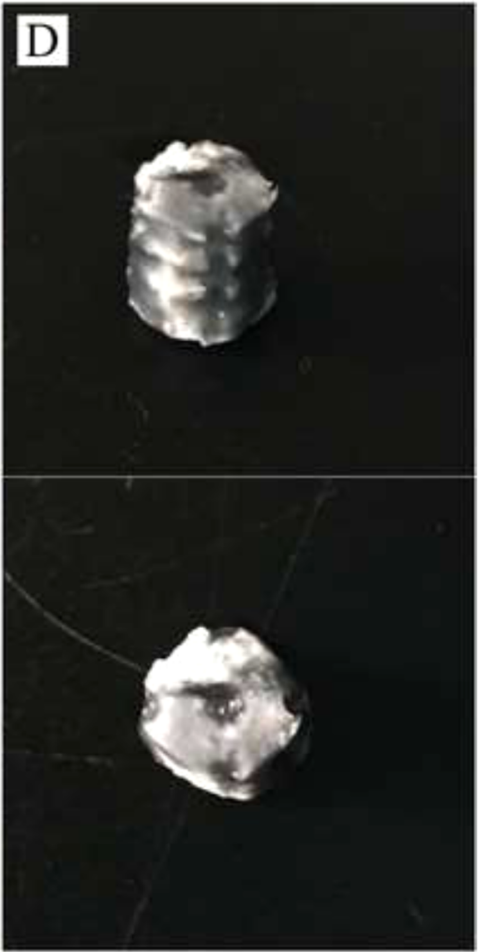

Fig. 1 COL-HA-PVA hydrogels preparation: A denatured PVA mold, the thickness of the PVA column (red arrow) was 1.2, 1.4, 1.6, 1.8, and $2.0 \mathrm{~mm}$, respectively, and the diameter of the denatured PVA mold

the HA-PVA hydrogels; (3) immersing the COL-HA-PVA composites into $0.5 \%$ genipin for $12 \mathrm{~h}$ to improve the crosslinking stability, and subsequently rinsing with $75 \%$ alcohol and double-distilled water to remove the residual genipin. Previous research revealed that gamma radiation is an effective method to sterilize PVA hydrogels and can further increase the crosslinking of the hybrid hydrogels [27]. The COL-HA-PVA hydrogels in our study were sterilized by gamma radiation using Cobalt-60 (25 KGy, $24 \mathrm{~h}$ ).

\subsubsection{Characterization of COL-HA-PVA hydrogels}

Macro-microstructure characterizations of the hybrid PVA hydrogels were conducted in the gel state using environmental scanning electron microscopy (ESEM), with a beam spot, low vacuum mode ( 0.75 Torr), and high pressure $(20 \mathrm{kV})$. The ESEM images were imported into Nano Measure software, and the diameters of the macropores were measured using a linear tool.

The moisture content of the hybrid hydrogels was measured by a weighing method. Specifically: the hybrid hydrogels were dried to a constant weight, recorded as W1; the dried sample was immersed in double-distilled water to reach a constant weight again, recorded as W2. The moisture content of the hybrid hydrogels was calculated by the following formula. (black arrow) was $8 \mathrm{~mm}$; B compound PVA including denatured PVA mold and HA-PVA emulsion; C HA-PVA hydrogels; D COL-HAPVA hydrogels

\section{Moisture content $=(\mathrm{W} 2-\mathrm{W} 1) / \mathrm{W} 2 \times 100 \%$}

\subsubsection{In vitro studies of COL-HA-PVA hydrogels}

The articular cartilages of goats were collected in a sterile tube and stored in a PBS solution containing penicillin (10,000 U/ $\mathrm{ml})$ and gentamicin $(5000 \mathrm{U} / \mathrm{ml})$ for $6 \mathrm{~h}$. The cartilage was cut into fragments of $\sim 1 \times 1 \times 1 \mathrm{~mm}^{3}$ using a surgical blade and rinsed with $\mathrm{PBS}$ solution three times, digested with trypsin $(25 \%, 5 \mathrm{ml})$ for $30 \mathrm{~min}$ and digested with type II collagenase $(0.2 \%, 5 \mathrm{ml})$ for $6 \mathrm{~h}$. The cell suspension was incubated in a humidified incubator $\left(37^{\circ} \mathrm{C}, 5 \% \mathrm{CO}_{2}\right)$ with chondrocyte basal medium (), and the medium was changed every 2 days until the chondrocytes were expanded to $90 \%$ confluency for further subculture. The density of the cell suspension was adjusted to $1 \times 10^{6} / \mathrm{mL}$ in the in vitro studies.

The diameter of the PVA thread $(1.2,1.4,1.6,1.8$, and $2.0 \mathrm{~mm}$ ) provided the basis of the grouping for the experiments in vitro. The sterilized hydrogels were washed with PBS solution. The cell suspension $\left(1 \times 10^{6} / \mathrm{mL}, 100 \mu \mathrm{L}\right)$ was then added to the sample and incubated at $5 \% \mathrm{CO}_{2}$ and $37^{\circ} \mathrm{C}$ for $1 \mathrm{~h}$. The chondrocyte culture medium $(500 \mathrm{ml}$ of basal medium, $25 \mathrm{ml}$ of FBS, $5 \mathrm{ml}$ of Chondrocyte Growth Supplement, and $5 \mathrm{ml}$ of penicillin/streptomycin solution) was then added to cover the hydrogels. The cell viability was studied by the cell adhesion rate on the first day, and the relative growth rate 


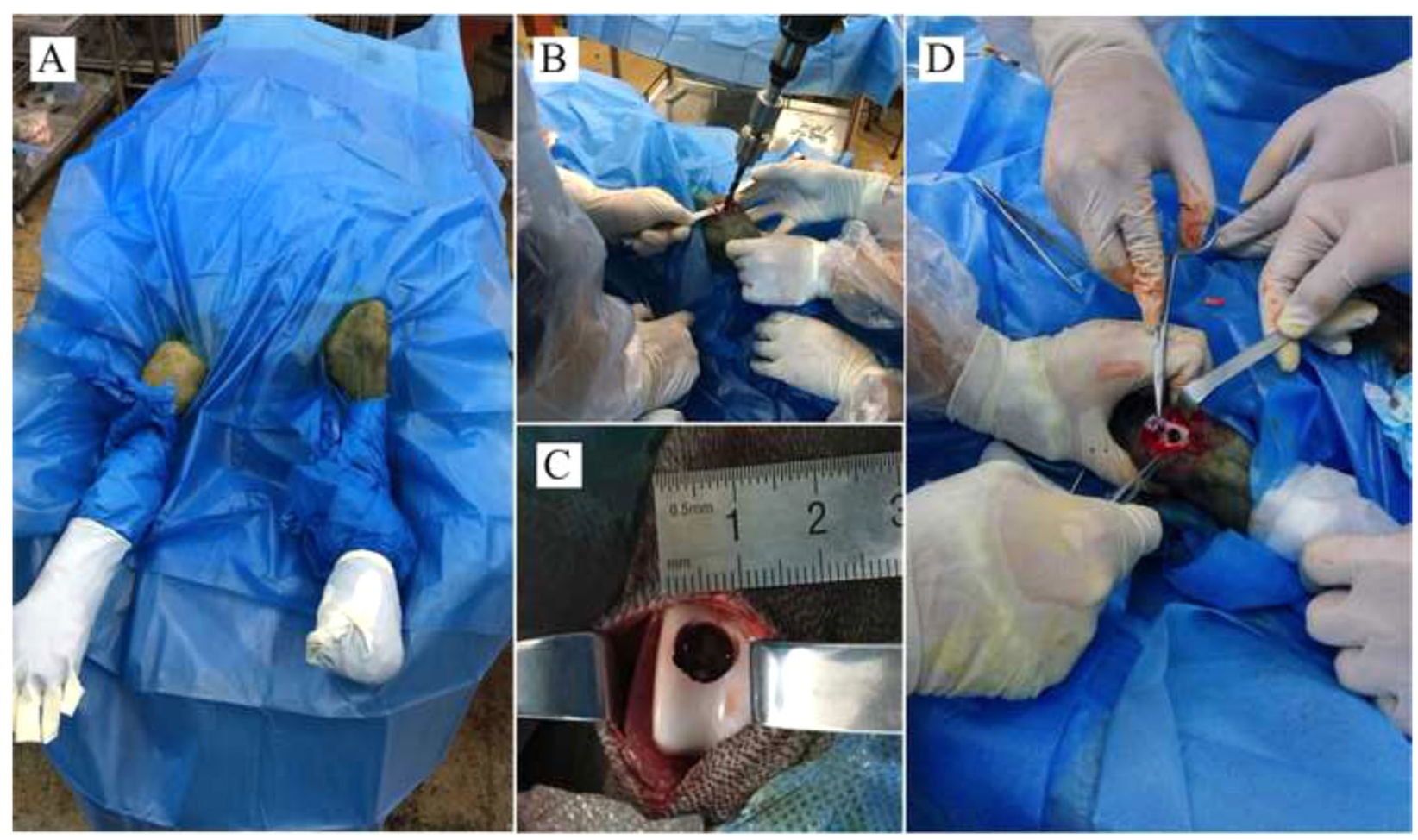

Fig. 2 Animal model preparation: A shaving and sterilizing around incision; B, C Osteochondral defects were created by an electric drill; D hydrogels implantation

(RGR) and ESEM observations on the third day, according to the protocol of previous studies [9, 28]. HA-PVA hydrogels (without COL microscaffolds) prepared by the above method were used as the control group, and a chondrocyte plate culture was used as the Blank group for RGR analysis. On the seventh day in vitro, these samples were fixed in $4 \%$ paraformaldehyde for $24 \mathrm{~h}$, and then embedded with paraffin for histological detection. The paraffin section was stained with hematoxylin and eosin (H\&E), and COL II was detected using immunohistochemistry (IHC), according to the manufacturer's protocol (Cyagen US, Inc). Histological analyses were performed using light microscopy.

\subsubsection{In vivo studies of COL-HA-PVA hydrogels}

Based on the results of the cell viability in vitro, ingrowth of chondrocytes was observed in all of the hydrogels. When the diameter of the denatured PVA column was $1.6 \mathrm{~mm}$, the hydrogels were more capable of cartilage ingrowth. Therefore, the COL-HA-PVA hydrogels with a PVA column of $1.6 \mathrm{~mm}$ were used for further in vivo experiments.

Ten 10-month-old goats were anesthetized intramuscularly (Sumianxin II, $0.1 \mathrm{ml} / \mathrm{kg}$ ). Both knee joints were exposed via a medial parapatellar approach after shaving and sterilizing around the incision (Fig. 2A). Osteochondral defects $(8 \mathrm{~mm}$ in diameter and $8 \mathrm{~mm}$ in depth) in the femoral trochlear were created by an electric drill $(8 \mathrm{~mm}$ in diameter and $8 \mathrm{~mm}$ in depth) (Fig. 2B, C). The cell-seeded (allogeneic cells) and cell-free hydrogels were implanted into the defects separately (Fig. 2D). The defects of the control group did not receive implants, except for routine suture. The goats returned to normal activity after recovery from anesthesia and received intramuscular injection of antibiotics for 3 days after operation (penicillin, per day: 100,000 U/kg). Wound conditions were recorded regularly. One month after operation, the goats were sacrificed, and the resected distal femur was collected for examination. Half of the samples were embedded in paraffin, and stained with $\mathrm{H} \& \mathrm{E}$, Safranin $\mathrm{O}$, and Toluidine Blue. The remaining samples were used to measure the content of COL1I and GAG by spectrophotometry. The samples were exposed to dimethylmethylene blue, and the relative expressions of COL1A2, AGGRECAN, and SOX9 were detected by RT-qPCR.

\subsubsection{Statistical analysis}

SPSS19.0 software was used for statistical analysis. The data were recorded as mean \pm standard deviation $(X \pm S)$. In accordance with normal distribution and homogeneity of variance, one-way ANOVA was used for data comparison among the groups, and an LSD test was used for pairwise comparison. Tamhane's T2 test was used when the variance was uneven. Statistical difference was identified as $p<0.05$. 
Fig. 3 Characterization of COLHA-PVA hydrogels: A, B microstructure of the COL-HAPVA hydrogels by ESEM, the macropores of HA-PVA hydrogels (red arrow) contained COL reticular structure (white arrow); $\mathbf{C}$ moisture content of COL-HA-PVA hydrogels; D macropore diameter formed by HA-PVA hydrogels
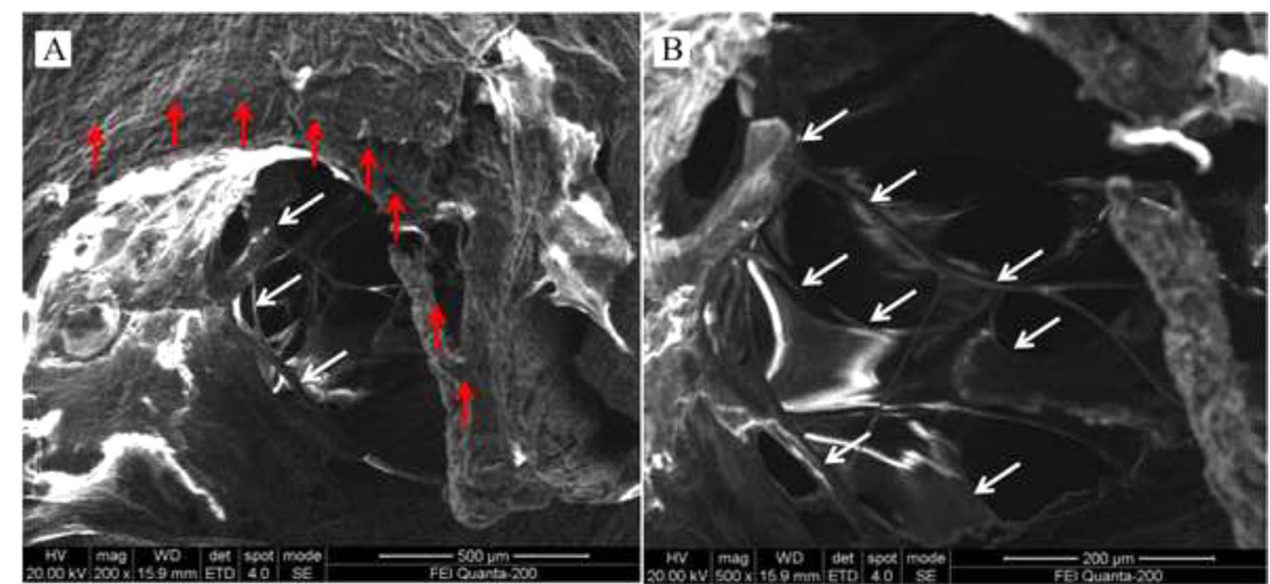

C

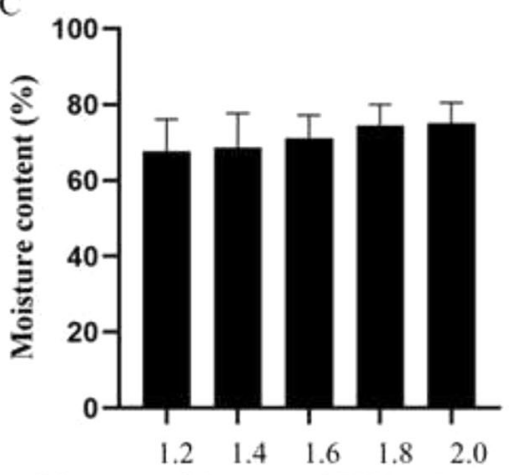

Diameter of denatured PVA column (mm)
$\mathrm{D}$

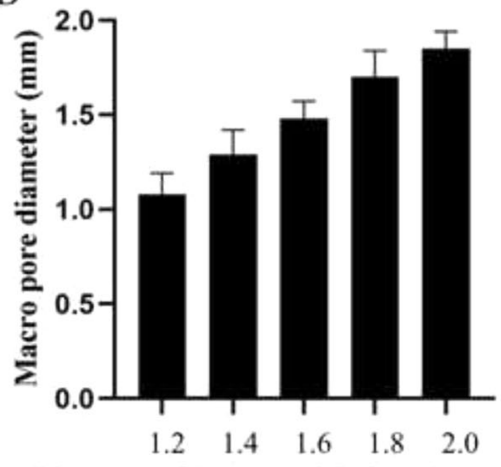

Diameter of denatured PVA column (mm)

\section{Results}

\subsection{Characterization of the COL-HA-PVA hydrogels}

The structures of the COL-HA-PVA hydrogels are demonstrated in Fig. 3A, B. The hybrid hydrogels have an interconnected macropore structure, and the macropores contained a COL reticular structure. As shown in Fig. 3C, the moisture content of each group was greater than $65 \%$ (range, 67.6-75.2\%). With an increase in denatured PVA, the moisture content increased; however, there was no significant difference among the groups $(p>0.05)$. The diameter of the macropore was slightly smaller than that of the inverted PVA column (range, 1.08-1.85 mm) (Fig. 3D), and the size of the macropore generally corresponds to the diameter of the denatured PVA column.

\subsection{In vitro studies of COL-HA-PVA hydrogels}

As shown in the ESEM images (Fig. 4A, B), chondrocytes were uniformly attached to the COL reticular structure. The adhesion rate and RGR of the hybrid hydrogels containing the COL reticular structure were significantly greater than that in the control group without COL $(p<0.05)$, and there were no significant differences among the COL-HA-PVA hydrogels $(p>0.05)$ (Fig. 4C, D). After 7 and 14 days of culture, H\&E staining exhibited new cartilage-like tissue formation in the macropores of HA-PVA hydrogels (Fig. 5), and IHC staining suggested the formation of cartilagespecific COL II (Fig. 6). Compared with the results of the 7-day culture, there was stronger staining of $\mathrm{H} \& \mathrm{E}$ and $\mathrm{COL}$ II at 14 days. The proliferation of chondrocytes and production of cartilage matrix were greatest when the diameter of the print-denatured PVA scaffold was $1.6 \mathrm{~mm}$.

\subsection{In vivo studies of the COL-HA-PVA hydrogels}

General observation of the repaired goat knees showed no signs of swelling, exudation, or lumps. As shown in Fig. 7, there was no invagination or bulging of the hydrogels in the defect areas, and there was no obvious edge between the implant and surrounding normal cartilage tissue. The new cartilage-like tissue around the defect was visible and closely adhered to the surrounding tissue. H\&E, Safranin O, and Toluidine blue staining showed that the chondrogenic matrix was more prominent in the cell-seeded group, followed by the Cell-free group, and only a small amount of cartilage-like matrix was produced in the control group (Fig. 8). IHC staining of COL II and COL IV was the most 
Fig. 4 Cell viability of COLHA-PVA hydrogels in vitro: $\mathbf{A}$, B microstructure of the COLHA-PVA hydrogels by ESEM on the 3rd day of culture, chondrocytes widely attach to COL reticular structure (white arrow); $\mathbf{C}$ adhesion rate of COLHA-PVA hydrogels; (D) RGR of COL-HA-PVA hydrogels. (cg control group; bg: blank group; $* p<0.05$, compared with hydrogels group)
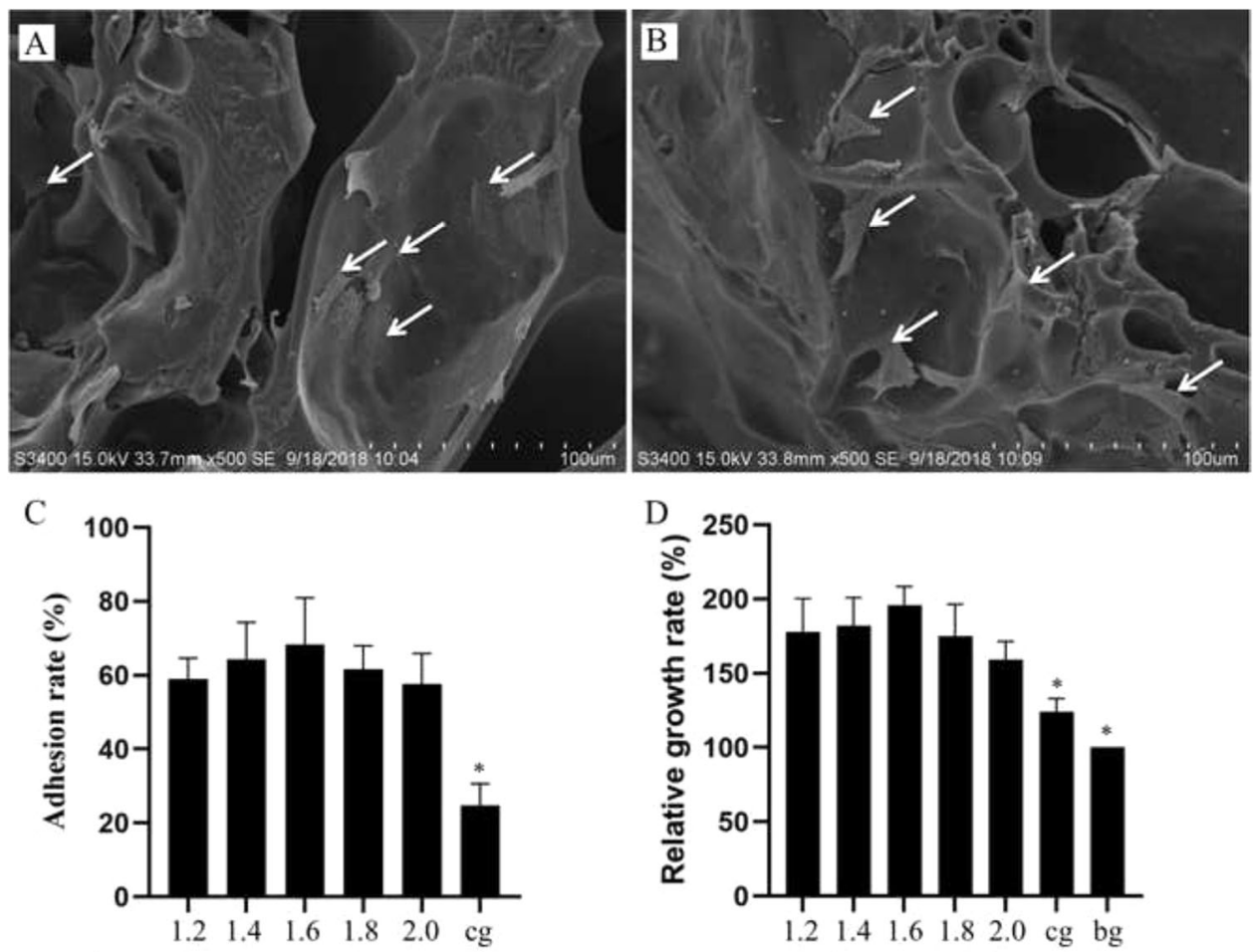

Diameter of denatured PVA column (mm)

Diameter of denatured PVA column (mm) significant in the cell-seeded group, followed by the cellfree group, and the control group was the weakest (Fig. 9).

The quantitative analyses of COL II and GAG are shown in Fig. 10. Specifically: the expression of COL II and GAG in the cell-seeded group was significantly greater than that in the other two groups $(p<0.05)$; there was no significant difference in the expression of COL II in the cell-free group and control group $(p>0.05)$; the expression of GAGs in the cell-free group was significantly greater than that in the control group $(p<0.05)$. The mRNA expression of COL II, AGGRECAN, and SOX9 are shown in Fig. 11. Specifically, AGGRECAN mRNA in the cell-seeded group was significantly greater than that other two groups $(p<0.05)$; there was no significant difference in the expression of AGGRECAN mRNA in the cell-free group and control group ( $p>0.05)$; the expression of AGGRECAN and SOX9 mRNA were the greatest in the cell-seeded group, followed by the cell-free group, and the control group was the lowest $(p<0.05)$.

\section{Discussion}

The first objective of the present study was to demonstrate the construction of new COL-HA-PVA hydrogels. The main part of the hybrid hydrogels was formed by the HAPVA hydrogel, and COL microscaffolds were formed in the macropores of the hydrogel, which allowed for cell adhesion and integration with peripheral native cartilage. The second objective was to determine the feasibility of the COL-HA-PVA hydrogels in cartilage repair by in vitro and in vivo experiments. Our results suggest the potential of the COL-HA-PVA hydrogels in cartilage repair.

Previous studies of PVA hydrogels suggest that more surface pore structures are formed in the freeze-thaw process rather than internal connected pores [29, 30], which suggests that 3DP can be used to construct PVA hydrogels with designed geometry and a well-defined structure [31]. In our research, the COL-HA-PVA hydrogels had an interconnected macropore structure and the macropores of the HA-PVA hydrogels contained a COL reticular structure. The interconnected macropore supports nutrient transport, while the COL micropore supports cell adhesion and subsequently cartilage ingrowth. In addition, the 3D geometry can be controlled through 3DP. The diameter of the macropore was slightly smaller than that of the inverted PVA column in our COL-HA-PVA hydrogels because of the swelling of the hydrogel [32]. Overall, the size of the macropore corresponds to the diameter of the denatured PVA column, which suggests that the macroscopic structure of the porous PVA hydrogels can be controlled by CAD [33].

Based on the in vitro experiments of the adhesion rate, RGR, and IHC, the hybrid hydrogels containing COL reticular structure significantly enhanced the viability of cell seeding, which suggests that the addition of COL improves 

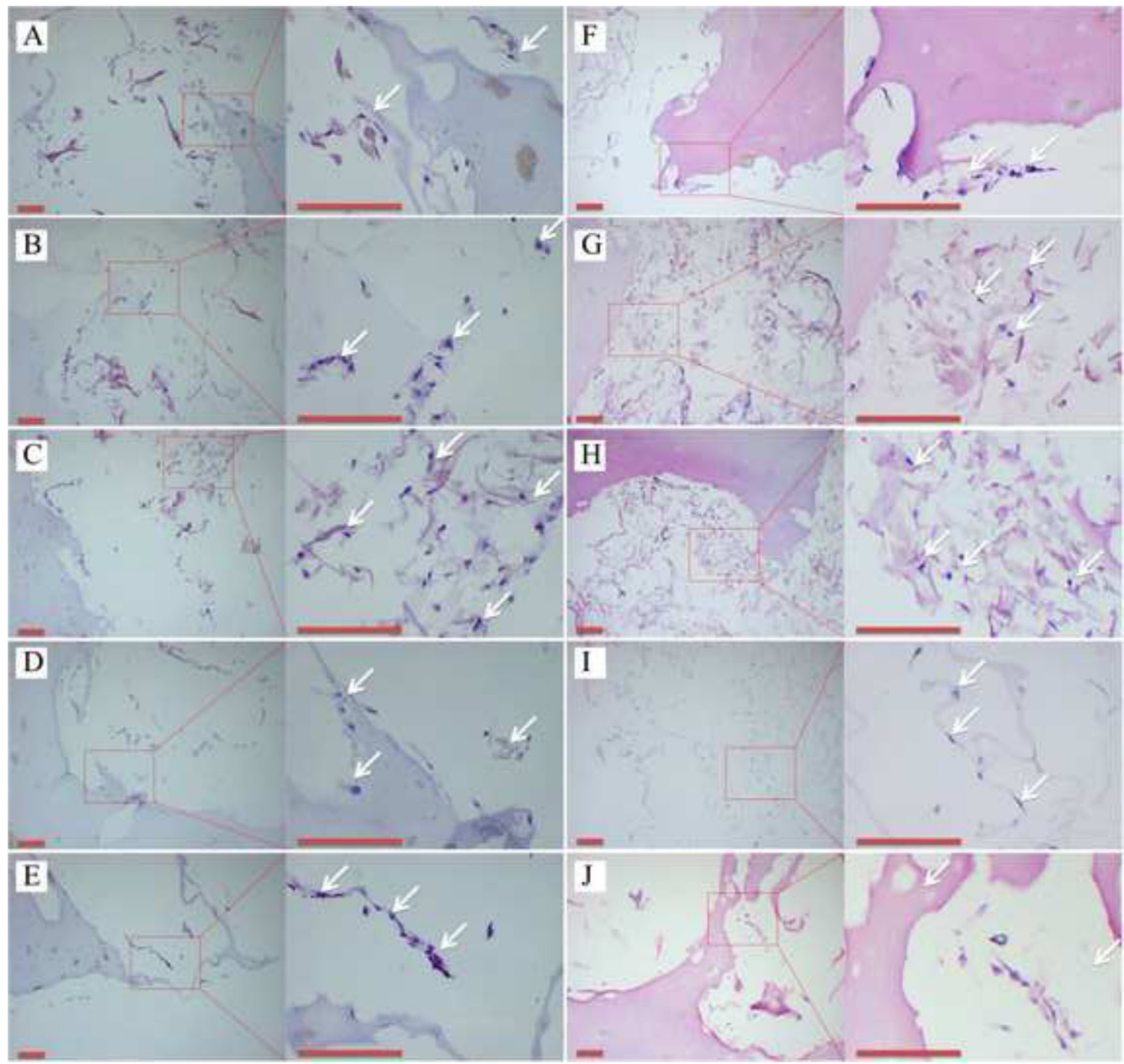

Fig. 5 Representative H\&E positive staining (white arrow) in vitro (scale bar: $100 \mathrm{~mm}$ ): A-E the diameter of PVA thread was 1.2, 1.4 1.6, 1.8 , and $2.0 \mathrm{~mm}$, respectively, after 7 days of culture; $\mathbf{F}-\mathbf{J}$ the diameter

of PVA thread was $1.2,1.4,1.6,1.8$, and $2.0 \mathrm{~mm}$, respectively, after 14 days of culture

the biocompatibility of PVA hydrogels. Various previous studies have shown that COL-based hydrogels support high cell viability [34-36]. The existence of Col, the main component of natural extracellular matrix, as a microscaffold in the hydrogel significantly increased the body surface area of cell adhesion. In addition, microstructures (such as pore size) of scaffolds can affect cell implantation and tissue regeneration [37, 38]. In our research, the COL-HA-PVA hydrogels contained more COL microscaffold, and the hydrogels were more capable of maintaining cell viability and forming cartilage in vitro when the diameter of the denatured PVA column was $1.6 \mathrm{~mm}$. We speculate that the pore diameter could affect the inoculation efficiency. The COL microscaffold and seeded cells were difficult to infiltrate when the macropore of the PVA hydrogels was relatively small $(1.2 \mathrm{~mm}$ and $1.4 \mathrm{~mm})$, while the $\mathrm{COL}$ microscaffold pore size did not support a stable structure

when the macropore was relatively large $(1.8 \mathrm{~mm}$ and $2.0 \mathrm{~mm}$ ). Therefore, the present study chose the hybrid hydrogel with an initial PVA diameter of $1.6 \mathrm{~mm}$ for experiment in vivo.

The goat was used as the animal model because the anatomical structure of the knee is similar to that of humans [39-41]. The full thickness of the knee cartilage of goats is only $2 \mathrm{~mm}$, and a simple cartilage defect substitute is difficult to fix firmly [42]. In addition, cartilage damage often accompanies damage to the subchondral bone. Many studies have suggested that cartilage damage and subchondral bone should be repaired [43, 44]. A cartilage defect with a diameter up to $3 \mathrm{~mm}$ can be repaired without intervention [45]. Therefore, large cylindrical osteochondral defects (diameter: $8 \mathrm{~mm}$, height: $8 \mathrm{~mm}$ ) were used in our research. Based on the IHC and molecular biology in vivo analysis, the COL-HA-PVA hydrogels promoted the repair of 


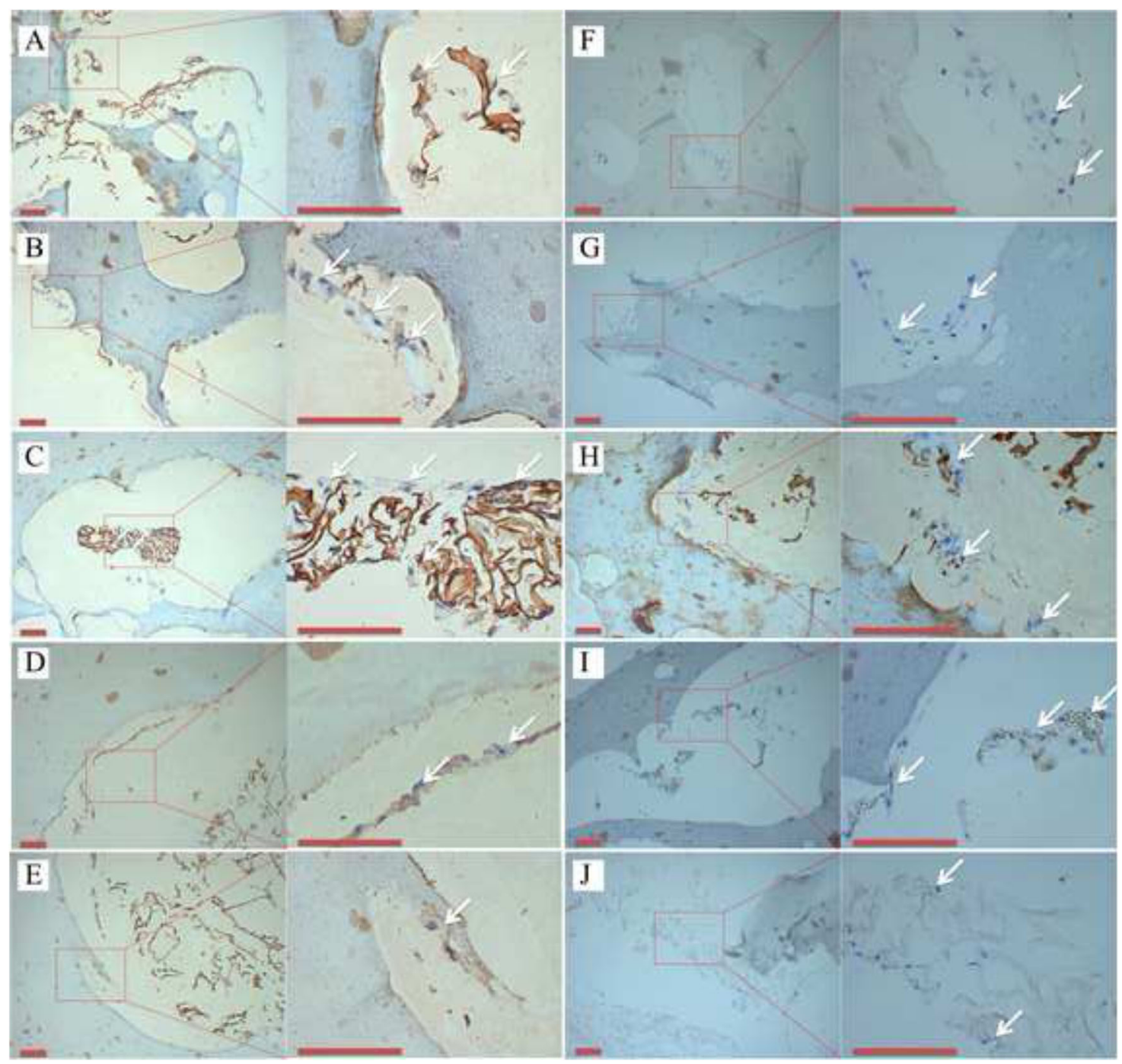

Fig. 6 Representative IHC staining of COL II displayed brown yellow or brown particles (white arrow) in vitro (scale bar: $100 \mathrm{~mm}$ ): A-E the diameter of PVA thread was 1.2, 1.4, 1.6, 1.8, and $2.0 \mathrm{~mm}$, respectively, after 7 days of culture; $\mathbf{F}-\mathbf{J}$ the diameter of PVA thread was $1.2,1.4,1.6,1.8$, and $2.0 \mathrm{~mm}$, respectively, after 14 days of culture
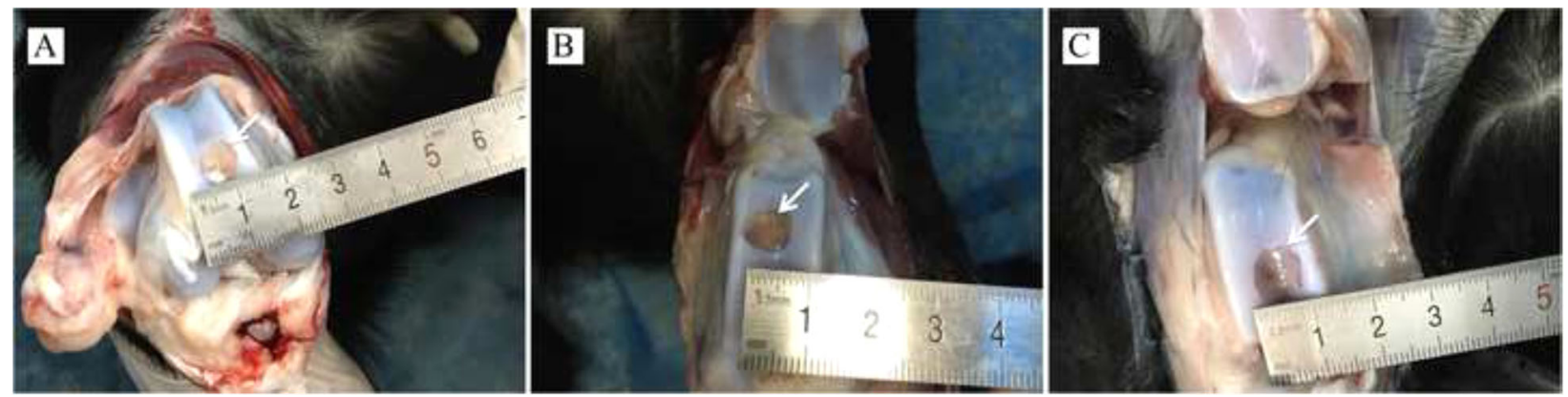

Fig. 7 General observation of defects, new cartilage-like tissue (white arrow) around the defect was visible: A COL-HA-PVA hydrogels with the cell-seeded group; B COL-HA-PVA hydrogels with cell-free group; $\mathbf{C}$ the control group without hydrogels 

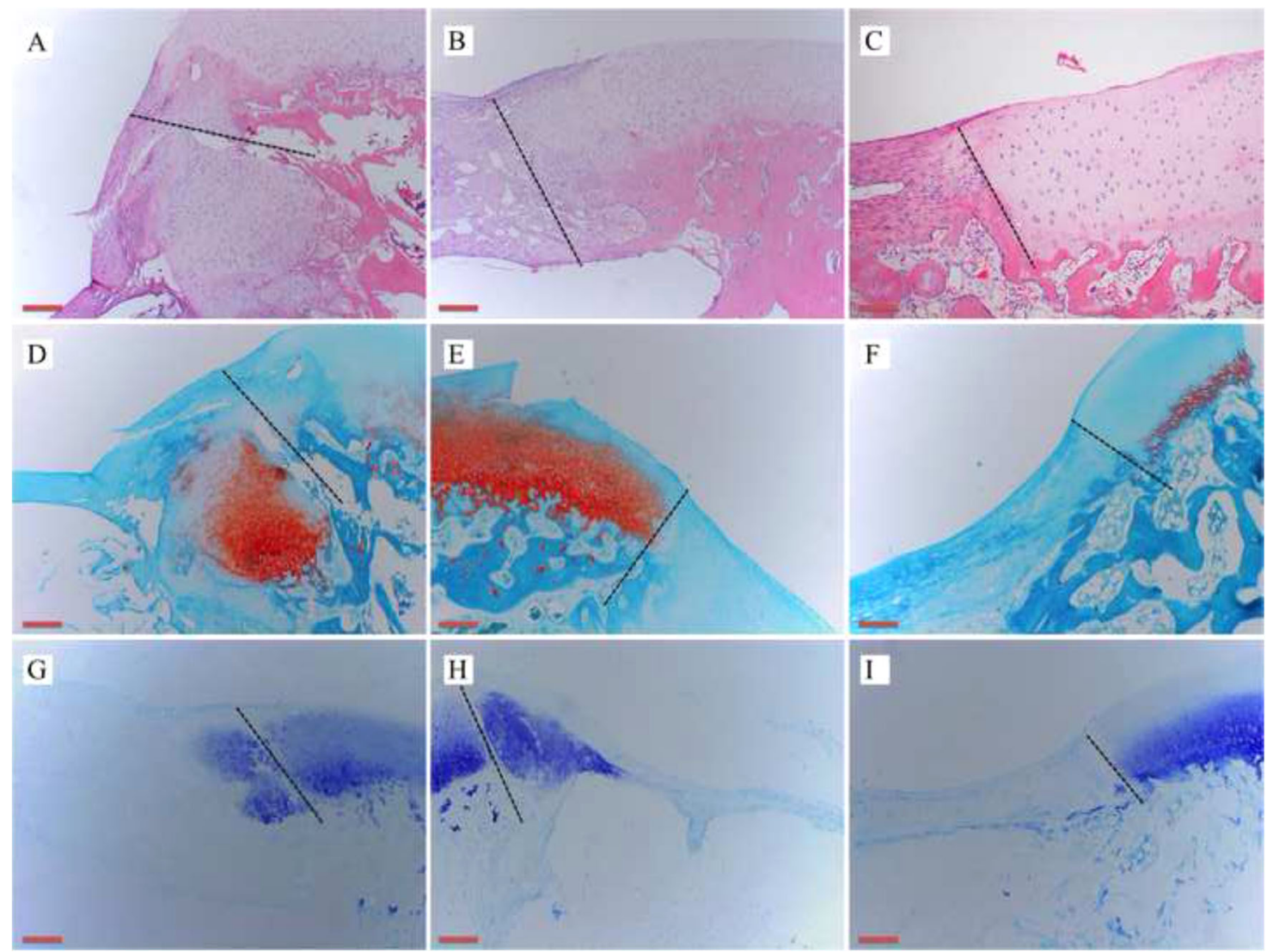

Fig. 8 Representative histological staining after 1 month of implantation, the black dotted lines represent the boundary between implantation and natural cartilage (scale bar: $100 \mathrm{~mm}$ ): A-C H\&E staining results in cell-seeded group, cell-free group, and control

group, respectively; D-F Safranin O staining results in cell-seeded group, cell-free group, and control group, respectively; G-I Toluidine blue staining results in cell-seeded group, cell-free group, and control group, respectively

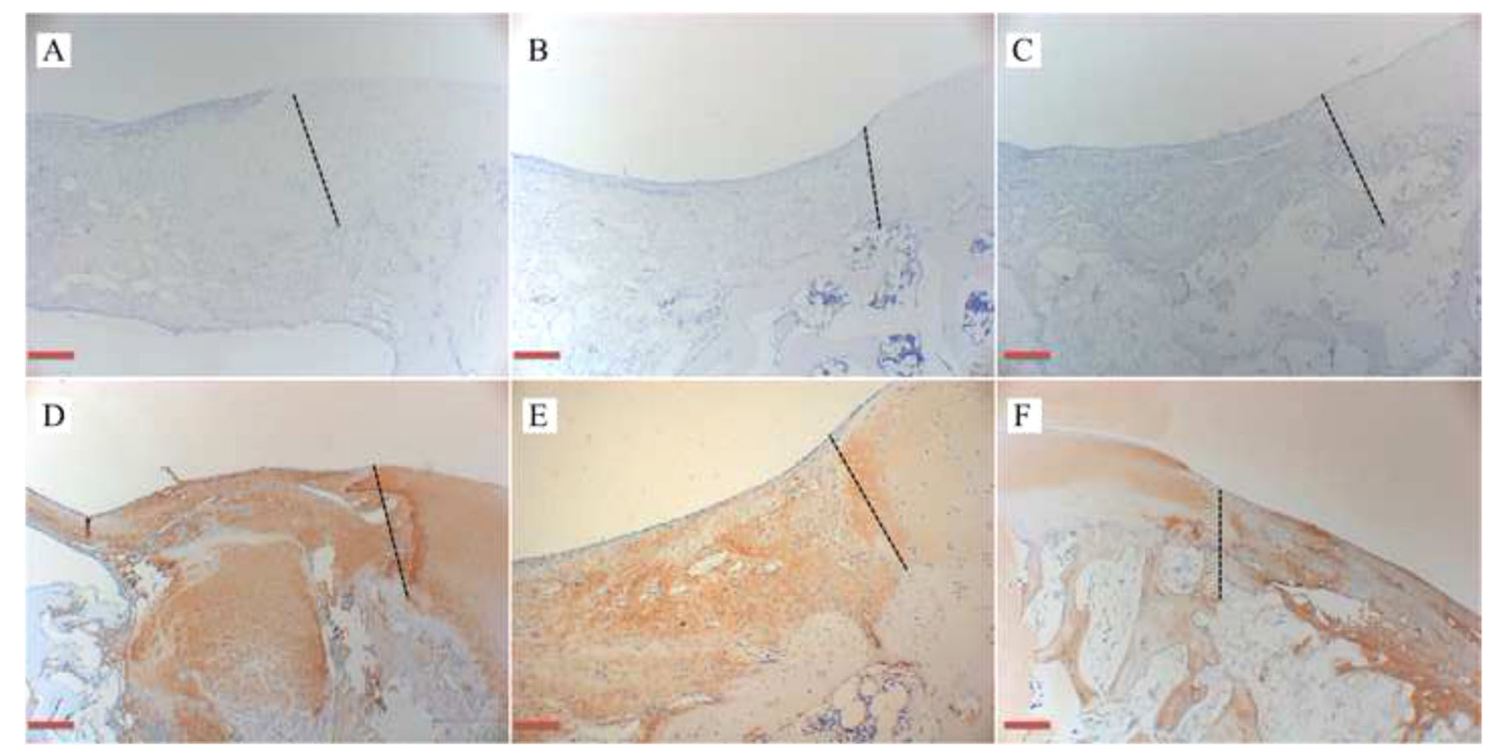

Fig. 9 Representative IHC staining after 1 month of implantation, the black dotted lines represent the boundary between implantation and natural cartilage (scale bar: $100 \mathrm{~mm}$ ): A-C IHC staining of COL II results in cell-seeded group, cell-free group, and control group, respectively; D-F IHC staining of COL IV results in cell-seeded group, cell-free group, and control group, respectively 
Fig. 10 The quantitative analyses of COL II (A) and GAG (B) by spectrophotometry. (sg: cell-seeded group; fg cellfree group; cg control group; $* p$ $<0.05)$
A

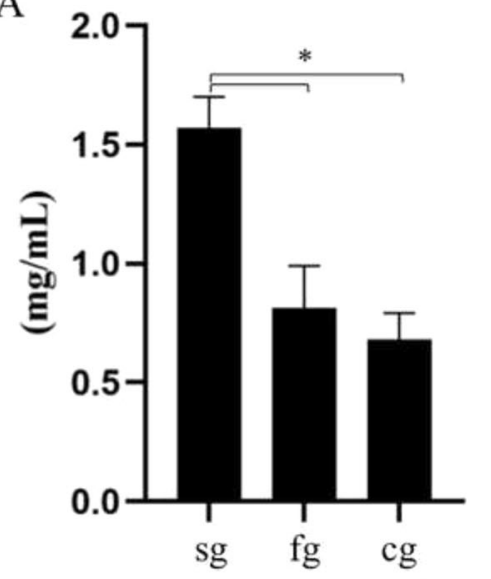

The expression of COL II

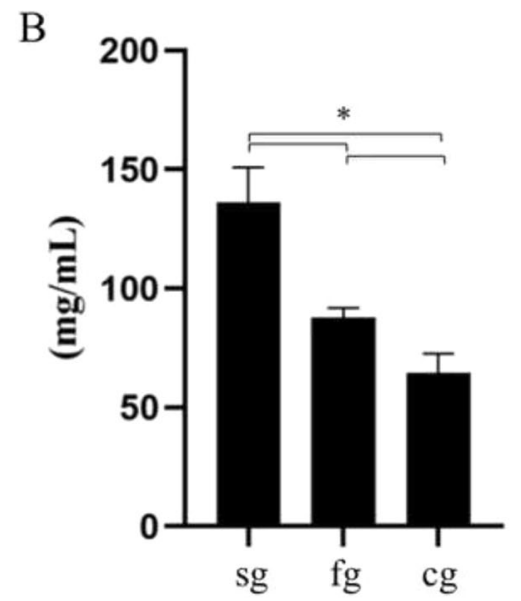

The expression of GAG cartilage defects, and hydrogels seeded with chondrocytes were more effective than the hydrogel only group (control). These results are consistent with other studies that have shown that a scaffold inoculated with cell has a better effect on cartilage repair $[46,47]$. The microfracture of subchondral bone helps in the healing process, although most of the neo-tissue might be fibrocartilage [48, 49]. Based on the results of IHC and molecular biology, a small amount of cartilage-like matrix was produced in the control group without hydrogel, which suggests that the goat cartilage has the ability for self-repair. In addition, the chondrogenic matrix was more prominent in the cell-seeded and cell-free scaffolds in this research; compared with the cell-free group, the cell-seeded group had more cartilage formation, corresponding to published research $[49,50]$.

Further studies are necessary for realization of the further application of COL-HA-PVA hydrogels. First, the mechanical properties of the materials, including compression, tension, shear, and friction, need to be further tested, and the mechanical properties can be optimized by structure or composition changes [51, 52]. Second, there are some differences between the biodegradable COL reticular structure and $\mathrm{COL}$ in natural cartilage, and the $\mathrm{COL}$ microscaffold in the hybrid hydrogels tends to be structurally unstable. Further study is needed to balance the degradation of COL and the formation of neo-tissue. Finally, longer periods of observation in vivo should be performed to verify the practicability of COL-HA-PVA hydrogels in cartilage defects.

\section{Conclusions}

COL-HA-PVA hydrogels were created using FDM printing, freeze-drying crosslinking, double steaming water demolding, and genipin crosslinking. In the hybrid PVA hydrogels,

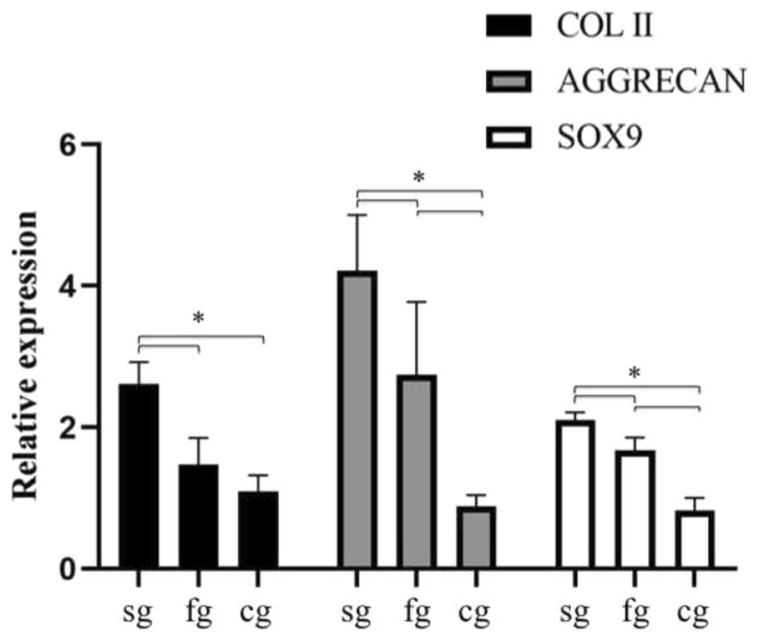

The expression of mRNA after 1 month implantation

Fig. 11 The relative expression of COL II, AGGRECAN and SOX9 by RT-qPCR. (sg: cell-seeded group; fg cell-free group; cg control group; $\left.{ }^{*} p<0.05\right)$

the HA-PVA hydrogels have an interconnected macropore structure, which simulates the characteristics of the viscoelastic material of natural cartilage, while the infilled degrading COL microscaffolds improved the biocompatibility of hydrogels, allowing for cell adhesion. The in vitro experiments revealed excellent cellular biocompatibility, and the hybrid hydrogels had more cartilage formation when the diameter of the print-denatured PVA scaffold was $1.6 \mathrm{~mm}$. The in vivo results showed that the COL-HA-PVA hydrogels could effectively repair cartilage defects, especially when inoculated with chondrocytes in advance. The results of this study indicate that the COL-HA-PVA hydrogels have promising application in cartilage repair.

Author contributions Experimental design: MZ, YH, JX. Material preparation: MZ, YH, WW. Performing in vitro experiments: MZ, 
WS, WL. Performing in vivo experiments: MZ, JX, WW, WL. Detection: MZ, WW. Drafting and revising of the article: MZ, RZ, JX, YH. All authors read and approved the final manuscript.

Funding This work was supported by the National Natural Science Foundation of China (Nos. 81672138 and 81501860).

\section{Compliance with ethical standards}

Conflict of interest The authors declare no competing interests.

Consent to participate All authors are fully involved in the study and preparation of the manuscript.

Consent for publication All authors gave written informed consent to involvement in this study.

Ethical approval The medical ethics committee of Xiangya Hospital Central South University gave ethical approval of this research.

Publisher's note Springer Nature remains neutral with regard to jurisdictional claims in published maps and institutional affiliations.

Open Access This article is licensed under a Creative Commons Attribution 4.0 International License, which permits use, sharing, adaptation, distribution and reproduction in any medium or format, as long as you give appropriate credit to the original author(s) and the source, provide a link to the Creative Commons license, and indicate if changes were made. The images or other third party material in this article are included in the article's Creative Commons license, unless indicated otherwise in a credit line to the material. If material is not included in the article's Creative Commons license and your intended use is not permitted by statutory regulation or exceeds the permitted use, you will need to obtain permission directly from the copyright holder. To view a copy of this license, visit http://creativecommons. org/licenses/by/4.0/.

\section{References}

1. Redler LH, Caldwell JM, Schulz BM, Levine WN. Management of articular cartilage defects of the knee. Phys Sportsmed. 2012;40:20-35. https://doi.org/10.3810/psm.2012.02.1948

2. Camp CL, Stuart MJ, Krych AJ. Current concepts of articular cartilage restoration techniques in the knee. Sports Health. 2014;6:265-73. https://doi.org/10.1177/1941738113508917

3. Takeda H, Nakagawa T, Nakamura K, Engebretsen L. Prevention and management of knee osteoarthritis and knee cartilage injury in sports. Br J Sports Med. 2011;45:304-9. https://doi.org/10.1136/ bjsm.2010.082321

4. Sherwood JC, Bertrand J, Eldridge SE, Dell'Accio F. Cellular and molecular mechanisms of cartilage damage and repair. Drug Discov Today. 2014;19:1172-7. https://doi.org/10.1016/j.drudis. 2014.05.014

5. Pap T, Korb-Pap A. Cartilage damage in osteoarthritis and rheumatoid arthritis-two unequal siblings. Nat Rev Rheumatol. 2015;11:606-15. https://doi.org/10.1038/nrrheum.2015.95

6. Pourbashir S, Shahrousvand M, Ghaffari M. Preparation and characterization of semi-IPNs of polycaprolactone/poly (acrylic acid)/cellulosic nanowhisker as artificial articular cartilage. Int $\mathbf{J}$ Biol Macromol. 2020;142:298-310. https://doi.org/10.1016/j. ijbiomac.2019.09.101
7. Meng Y, Cao J, Chen Y, Yu Y, Ye L. 3D printing of a poly(vinyl alcohol)-based nano-composite hydrogel as an artificial cartilage replacement and the improvement mechanism of printing accuracy. J Mater Chem B. 2020;8:677-90. https://doi.org/10.1039/ c9tb02278c

8. Pereira DR, Reis RL, Oliveira JM. Layered scaffolds for osteochondral tissue engineering. Adv Exp Med Biol. 2018;1058:193-218. https://doi.org/10.1007/978-3-319-76711-6_ 9

9. Cao Y, Xiong D, Wang K, Niu Y. Semi-degradable porous poly (vinyl alcohol) hydrogel scaffold for cartilage repair: Evaluation of the initial and cell-cultured tribological properties. J Mech Behav Biomed Mater. 2017;68:163-72. https://doi.org/10.1016/j. jmbbm.2017.02.001

10. Li F, Wang A, Wang C. Analysis of friction between articular cartilage and polyvinyl alcohol hydrogel artificial cartilage. J Mater Sci Mater Med. 2016;27:87 https://doi.org/10.1007/s10856016-5700-y

11. Scholten PM, Ng KW, Joh K, Serino LP, Warren RF, Torzilli PA, et al. A semi-degradable composite scaffold for articular cartilage defects. J Biomed Mater Res A. 2011;97:8-15. https://doi.org/10. 1002/jbm.a.33005

12. Speer DP, Chvapil M, Volz RG, Holmes MD. Enhancement of healing in osteochondral defects by collagen sponge implants. Clin Orthop Relat Res. 1979;144:326-35.

13. Maiolo AS, Amado MN, Gonzalez JS, Alvarez VA. Development and characterization of Poly (vinyl alcohol) based hydrogels for potential use as an articular cartilage replacement. Mater Sci Eng C Mater Biol Appl. 2012;32:1490-5. https://doi.org/10.1016/j. msec.2012.04.030

14. Baker MI, Walsh SP, Schwartz Z, Boyan BD. A review of polyvinyl alcohol and its uses in cartilage and orthopedic applications. J Biomed Mater Res B Appl Biomater. 2012;100:1451-7. https://doi.org/10.1002/jbm.b.32694

15. Zhou H, Wang Z, Cao H, Hu H, Luo Z, Yang X, et al. Genipincrosslinked polyvinyl alcohol/silk fibroin/nano-hydroxyapatite hydrogel for fabrication of artificial cornea scaffolds-a novel approach to corneal tissue engineering. J Biomater Sci Polym Ed. 2019;30:1604-19. https://doi.org/10.1080/09205063.2019. 1652418

16. Yla-Outinen L, Harju V, Joki T, Koivisto JT, Karvinen J, Kellomaki $\mathrm{M}$, et al. Screening of hydrogels for human pluripotent stem cell-derived neural cells: hyaluronan-polyvinyl alcoholcollagen-based interpenetrating polymer network provides an improved hydrogel scaffold. Macromol Biosci. 2019;19:e1900096 https://doi.org/10.1002/mabi.201900096

17. Chen K, Chen G, Wei S, Yang X, Zhang D, Xu L. Preparation and property of high strength and low friction PVA-HA/PAA composite hydrogel using annealing treatment. Mater Sci Eng C Mater Biol Appl. 2018;91:579-88. https://doi.org/10.1016/j.msec.2018. 05.080

18. Bates NM, Heidenreich HE, Fallon ME, Yao Y, Yim EKF, Hinds MT, et al. Bioconjugation of a collagen-mimicking peptide onto poly(vinyl alcohol) encourages endothelialization while minimizing thrombosis. Front Bioeng Biotechnol. 2020;8:621768 https://doi.org/10.3389/fbioe.2020.621768

19. Su W, Hu Y, Zeng M, Li M, Lin S, Zhou Y, et al. Design and evaluation of nano-hydroxyapatite/poly(vinyl alcohol) hydrogels coated with poly(lactic-co-glycolic acid)/nano-hydroxyapatite/ poly(vinyl alcohol) scaffolds for cartilage repair. J Orthop Surg Res. 2019;14:446 https://doi.org/10.1186/s13018-019-1450-0

20. Masri C, Chagnon G, Favier D. Influence of processing parameters on the macroscopic mechanical behavior of PVA hydrogels. Mater Sci Eng C Mater Biol Appl. 2017;75:769-76. https:// doi.org/10.1016/j.msec.2017.02.045 
21. Chong SF, Smith AA, Zelikin AN. Microstructured, functional PVA hydrogels through bioconjugation with oligopeptides under physiological conditions. Small. 2013;9:942-50. https://doi.org/ 10.1002/smll.201201774

22. Li P, Pan L, Liu D, Tao Y, Shi SQ. A bio-hygromorph fabricated with fish swim bladder hydrogel and wood flour-filled polylactic acid scaffold by 3D printing. Materials. 2019;12. https://doi.org/ 10.3390/ma12182896.

23. Luo Y, Wei X, Huang P. 3D bioprinting of hydrogel-based biomimetic microenvironments. J Biomed Mater Res B Appl Biomater. 2019;107:1695-705. https://doi.org/10.1002/jbm.b.34262

24. Liu F, Li W, Liu H, Yuan T, Yang Y, Zhou W, et al. Preparation of 3D printed chitosan/polyvinyl alcohol double network hydrogel scaffolds. Macromol Biosci. 2021:e2000398. https://doi.org/10. 1002/mabi.202000398.

25. Pan Y, Xiong D, Gao F. Viscoelastic behavior of nanohydroxyapatite reinforced poly(vinyl alcohol) gel biocomposites as an articular cartilage. J Mater Sci Mater Med. 2008;19:1963-9. https://doi.org/10.1007/s10856-007-3280-6

26. Pan Y, Xiong D. Study on compressive mechanical properties of nanohydroxyapatite reinforced poly(vinyl alcohol) gel composites as biomaterial. J Mater Sci Mater Med. 2009;20:1291-7. https:// doi.org/10.1007/s10856-008-3679-8

27. Pohan G, Mattiassi S, Yao Y, Zaw AM, Anderson DEJ, Cutiongco MFA, et al. Effect of ethylene oxide sterilization on polyvinyl alcohol hydrogel compared with gamma radiation. Tissue Eng Part A 2020;26:1077-90. https://doi.org/10.1089/ten. TEA.2020.0002

28. Hou P, Zhang N, Wu R, Xu W, Hou Z. Photo-cross-linked biodegradable hydrogels based on n-arm-poly(ethylene glycol), poly (epsilon-caprolactone) and/or methacrylic acid for controlled drug release. J Biomater Appl. 2017;32:511-23. https://doi.org/10. 1177/0885328217730465

29. Oliveira AS, Seidi O, Ribeiro N, Colaco R, Serro AP. Tribomechanical comparison between PVA hydrogels obtained using different processing conditions and human cartilage. Materials. 2019;12. https://doi.org/10.3390/ma12203413.

30. Cardoso TP, Ursolino AP, Casagrande PM, Caetano EB, Mistura DV, Duek EA. In vivo evaluation of porous hydrogel pins to fill osteochondral defects in rabbits. Rev Bras Ortop. 2017;52:95-102. https://doi.org/10.1016/j.rboe.2016.03.009

31. Hu Y, Ma S, Yang Z, Zhou W, Du Z, Huang J, et al. Facile fabrication of poly(L-lactic acid) microsphere-incorporated calcium alginate/hydroxyapatite porous scaffolds based on Pickering emulsion templates. Colloids Surf B Biointerfaces. 2016;140:382-91. https://doi.org/10.1016/j.colsurfb.2016.01.005

32. Liu Y, Vrana NE, Cahill PA, McGuinness GB. Physically crosslinked composite hydrogels of PVA with natural macromolecules: structure, mechanical properties, and endothelial cell compatibility. J Biomed Mater Res B Appl Biomater. 2009;90:492-502. https://doi.org/10.1002/jbm.b.31310

33. Gu BK, Choi DJ, Park SJ, Kim YJ, Kim CH. 3D bioprinting technologies for tissue engineering applications. Adv Exp Med Biol. 2018;1078:15-28. https://doi.org/10.1007/978-981-130950-2_2

34. Frayssinet A, Petta D, Illoul C, Haye B, Markitantova A, Eglin D, et al. Extracellular matrix-mimetic composite hydrogels of crosslinked hyaluronan and fibrillar collagen with tunable properties and ultrastructure. Carbohydr Polym. 2020;236:116042 https:// doi.org/10.1016/j.carbpol.2020.116042

35. Gilarska A, Lewandowska-Lancucka J, Guzdek-Zajac K, Karewicz A, Horak W, Lach R, et al. Bioactive yet antimicrobial structurally stable collagen/chitosan/lysine functionalized hyaluronic acid - based injectable hydrogels for potential bone tissue engineering applications. Int J Biol Macromol. 2019. https://doi. org/10.1016/j.ijbiomac.2019.11.052.
36. Yang X, Lu Z, Wu H, Li W, Zheng L, Zhao J. Collagen-alginate as bioink for three-dimensional (3D) cell printing based cartilage tissue engineering. Mater Sci Eng C Mater Biol Appl. 2018;83:195-201. https://doi.org/10.1016/j.msec.2017.09.002

37. Engler AJ, Sen S, Sweeney HL, Discher DE. Matrix elasticity directs stem cell lineage specification. Cell. 2006;126:677-89. https://doi.org/10.1016/j.cell.2006.06.044

38. Stenhamre H, Nannmark U, Lindahl A, Gatenholm P, Brittberg M. Influence of pore size on the redifferentiation potential of human articular chondrocytes in poly(urethane urea) scaffolds. J Tissue Eng Regen Med. 2011;5:578-88. https://doi.org/10.1002/ term. 350

39. Liu Y, Li D, Yin Z, Luo X, Liu W, Zhang W, et al. Prolonged in vitro precultivation alleviates post-implantation inflammation and promotes stable subcutaneous cartilage formation in a goat model. Biomed Mater. 2016;12:015006 https://doi.org/10.1088/ 1748-605X/12/1/015006

40. Hunziker EB. Tissue engineering of bone and cartilage. From the preclinical model to the patient. Novartis Found Symp. 2003;885:239-41.

41. Kitamura N, Yokota M, Kurokawa T, Gong JP, Yasuda K. In vivo cartilage regeneration induced by a double-network hydrogel: Evaluation of a novel therapeutic strategy for femoral articular cartilage defects in a sheep model. J Biomed Mater Res A. 2016;104:2159-65. https://doi.org/10.1002/jbm.a.35745

42. Jackson DW, Lalor PA, Aberman HM, Simon TM. Spontaneous repair of full-thickness defects of articular cartilage in a goat model. A preliminary study. J Bone Jt Surg Am. 2001;83:53-64. https://doi.org/10.2106/00004623-200101000-00008

43. Kon E, Robinson D, Shani J, Alves A, Di Matteo B, Ashmore K, et al. Reconstruction of large osteochondral defects using a hemicondylar aragonite-based implant in a caprine model. Arthroscopy. 2020. https://doi.org/10.1016/j.arthro.2020.02.026.

44. Wei X, Liu B, Liu G, Yang F, Cao F, Dou X, et al. Mesenchymal stem cell-loaded porous tantalum integrated with biomimetic 3D collagen-based scaffold to repair large osteochondral defects in goats. Stem Cell Res Ther. 2019;10:72 https://doi.org/10.1186/ s13287-019-1176-2

45. Butnariu-Ephrat M, Robinson D, Mendes DG, Halperin N, Nevo Z. Resurfacing of goat articular cartilage by chondrocytes derived from bone marrow. Clin Orthop Relat Res. 1996;330:234-43. https://doi.org/10.1097/00003086-199609000-00031

46. Nixon AJ, Sparks HD, Begum L, McDonough S, Scimeca MS, Moran N, et al. Matrix-induced autologous chondrocyte implantation (MACI) using a cell-seeded collagen membrane improves cartilage healing in the equine model. J Bone Jt Surg Am. 2017;99:1987-98. https://doi.org/10.2106/JBJS.16.00603

47. Horbert V, Xin L, Foehr P, Brinkmann O, Bungartz M, Burgkart $\mathrm{RH}$, et al. In vitro analysis of cartilage regeneration using a collagen type I hydrogel $(\mathrm{CaReS})$ in the bovine cartilage punch model. Cartilage 2019;10:346-63. https://doi.org/10.1177/ 1947603518756985

48. Makris EA, Gomoll AH, Malizos KN, Hu JC, Athanasiou KA. Repair and tissue engineering techniques for articular cartilage. Nat Rev Rheumatol. 2015;11:21-34. https://doi.org/10.1038/ nrrheum.2014.157

49. Chen M, Li Y, Liu S, Feng Z, Wang H, Yang D, et al. Hierarchical macro-microporous WPU-ECM scaffolds combined with Microfracture Promote in Situ Articular Cartilage Regeneration in Rabbits. Bioact Mater. 2021;6:1932-44. https://doi.org/10.1016/j. bioactmat.2020.12.009

50. Ott LM, Vu CH, Farris AL, Fox KD, Galbraith RA, Weiss ML, et al. Functional reconstruction of tracheal defects by proteinloaded, cell-seeded, fibrous constructs in rabbits. Tissue Eng Part A. 2015;21:2390-403. https://doi.org/10.1089/ten.TEA.2015. 0157 
51. Roushangar Zineh B, Shabgard MR, Roshangar L. An experimental study on the mechanical and biological properties of bioprinted alginate/halloysite nanotube/methylcellulose/Russian olive-based scaffolds. Adv Pharm Bull. 2018;8:643-55. https:// doi.org/10.15171/apb.2018.073
52. Wang C, Yue H, Huang W, Lin X, Xie X, He Z, et al. Cryogenic $3 \mathrm{D}$ printing of heterogeneous scaffolds with gradient mechanical strengths and spatial delivery of osteogenic peptide/TGF-betal for osteochondral tissue regeneration. Biofabrication. 2020. https:// doi.org/10.1088/1758-5090/ab7ab5. 